Original Article

\title{
FIRST IDENTIFICATION OF NANOPARTICLES ON THORAX, ABDOMEN AND WINGS OF THE WORKER BEE APIS DORSATA FABRICIUS
}

\author{
Atanu Bhattacharyya' \\ Shashidhar Viraktamath² \\ Fani Hatjina ${ }^{3 *}$ \\ Santanu Bhattacharyya ${ }^{4}$ \\ Bhaktibhavana Rajankar² \\ Amitava Patra ${ }^{4}$ \\ ${ }^{1}$ Nanotechnology Section, Department of Biomedical Engineering, Rajiv Gandhi \\ Institute of Technology and Research Center, Cholanagar, R.T. Nagar Post, Hebbal, \\ 560032 Bangalote, India \\ 2Department of Entomology, University of Agricultural Sciences, 58005 Dharwad, \\ Karnataka, India \\ ${ }^{3}$ Division of Apiculture, Institute of Animal Sciences, Hellenic Agriculture Organiza- \\ tion "DEMETER" , 63200 Nea Moudania, Greece \\ ${ }^{4}$ Department of Material Sciences, Indian Association for the Cultivation of Science, \\ Jadavpur, 700032 Kolkata, India \\ *Corresponding author: fhatjina@instmelissocomias.gr \\ Received 25 September 2015; accepted 29 February 2016
}

A bstract

The presence of nanoparticles on the body of the honeybee Apis dorsata Fabricius, was investigated for the first time to better understand the bee's behaviour. These have been observed by using Scanning Electron Microscopy (SEM), Transmission Electron Microscopy (TEM) and confirmed by Atomic Force Microscopy (AFM). Our study clearly denotes that the Indian rock honey bee Apis dorsata possess calcium silicate and calcium phosphate nanoparticles on its body surface of $5-50 \mathrm{~nm}$ in diameter. In particular, the nanoparticles on the abdomen and thorax of $A$. dorsata have an average diameter of about 10 nanometers and they are smaller than those found on wings of the same bees which are about 20 nanometers. The nanoparticles found are different of the ones previously observed on honey bees or other insects. The origin and role of these natural nanoparticles on the body of the Indian rock bee need to be to be further investigated; more research in the subject might raise important aspects in relation to the conservation of these unique pollinators.

Keywords: nanoparticles, calcium silicate, calcium phosphate, Apis dorsata Fabricius, behaviour, pollinator

\section{INTRODUCTION}

\section{General}

It is a well known fact that the honey bee is a major pollinator of many of our food crops such as almonds, apples, avocados, blueberries, cantaloupes, cherries, cranberries, cucumbers, sunflowers, watermelon, and there are many other crops that rely on honey bees for pollination. The honey bee's economical role in worldwide pollination has been valued to be around 153 billion Euros in the year 2005 (Gallai et al., 2009) although the bee's primary interest is the 'search for food'. The dance language of the honey bees (Apis spp.) is one of the best known communicative adaptive feature among the honey bees (von Frisch, 1967; Gould, 1976). This language of honey bee is used to convey landscape information to other nest mates. The geomagnetic field has been shown to have an effect on the performance of the waggle dance of $A$. mellifera L. (Lindauer et al., 1986). More specifically, it has been shown that honey bees use geomagnetic field information for 
orientation, homing, and foraging (Binhi, 2004). Furthermore, it has been reported that honey bees posses large numbers ( 105) of super crystals. The crystals are called nanoparticles because their diameter is $>100 \mathrm{~nm}$. The word "nano" developed from the Greek word 'nanos' meaning "dwarf". In more technical terms, the word "nano" means 10-9 or one billionth of something. For example, the size of a nanoparticle is usually between 10-100 nm while viruses are between 20-450 nm, proteins between 5-50 nm, and genes between $2 \mathrm{~nm}$ wide by 10-100 nm long.

Up till now, those nanoparticles found in the bee abdomens ranged between 30 and $35 \mathrm{~nm}$ in diameter. They were assumed to be involved in magnetic field detection (Gould et al., 1980), probably due to iron protein ferritin and the ferrimagnetic responses of nanoscale magnetite $\left(\mathrm{Fe}_{3} \mathrm{O}_{4}\right)$ particles (Desoil et al., 2005). Nanoparticles were also found in body parts of other social insects, such as ants (Wajnberg et al., 2004; Abracado et al., 2005), termites (Alves et al., 2004), and meliponinae bees (Lucano et al., 2006).

Nanoparticles, in general, demonstrate unique characteristics with elevated strength, high electrical conductivity, and extra chemical reactivity (Nykypanchuk et al., 2008), as well as distinctive chemical, physical, and biological properties (Leiderer \& Dekorsy, 2008; Bhattacharyyal et al., 2008; Sabbour, 2013). That is why nanotechnology has been increasingly used in many fields as well as in agriculture (Gul et al., 2014).

Most studies concerning nanoparticles on bees have been performed on $A$. mellifera bees. Our study, however, demonstrates for the first time that the rock bee, $A$. dorsata $\mathrm{F}$., possess nanoparticles on its body surface. These particles have been identified by Scanning Electron Microscopy (SEM), and Transmission Electron Microscopy (TEM), and confirmed by Atomic Force Microscopy (AFM). The role that these particles could play on the behaviour of $A$. melifera dorsata is discussed.

\section{Background information on Apis dorsata Fabricius}

Apis dorsata Fabricius honey bees are the second largest species of honey bees. Apis dorsata $\mathrm{F}$. is commonly called the rock bee or giant bee. It is distributed throughout the Indo-Malayan region. It occurs in India, Pakistan, Sri Lanka, Nepal, and southern China, northern Burma, Indonesia, and all throughout the Philippine islands (Koeniger \& Koeniger, 1980; Ruttner, 1988).

Apis dorsata Fabricius construct single and huge nests under open conditions on tall trees, cliffs of rocks, tanks, buildings etc. An aggregation of colonies on a particular nesting site is a very common feature seen in this species. The shape of the comb is more or less semicircular or cuneiform. The surface of the comb varies from 0.1 to more than 1 square meter. The comb contains a thick honey comb with a thickness of $15-20 \mathrm{~cm}$ in the high section of the comb; a brood comb of 3-4 cm thick. Pollen is stored between the two zones. A functional division of the colony, like nest service, a protective curtain, and a mouth or active zone, is also present (Neupane et al., 2013).

The differences among the different castes (i.e. the workers, drones, and the queen) are very small. Worker and drone cells are also of the same size except that the drone cell capping is elevated and flat. The queen is slightly larger than the worker. The developmental periods of the worker, queen, and drone are 16-20, 13-13.5, and 20-23.5 days, respectively. The migratory distance can be up to $200 \mathrm{~km}$ and on the way, they may stop 2 to 3 times. These honey bees are known to forage throughout the day. This is the only species of honey bees foraging even during bright night hours. The extrapolated sun is used for compass orientation and not the position of the moon. These honey bees are also attracted to street lights (Dyer, 1985).

Apis dorsata $F$. are the most dominant pollinators visiting all agricultural, horticultural, and farm crops. They are quite predominant on crops like sunflower, niger, sesame, mustard, cotton, coconut, cardamom, coffee, fruit, and 
vegetables. The foraging range of these bees is more than $5 \mathrm{~km}$.

\section{MATERIAL AND METHODS}

Sample preparation for Field Emission Scanning Electron Microscopy (FE-SEM)

The bees were collected from the southern part of Dharawar, in the southern Indian state of Karnataka. Nanoparticles were determined on the abdomen, thorax, and wings of the bees. All samples were initially washed with double distilled water (DDW). For fixation, they were kept in glutaraldehyde $2.5 \%$ in $0.1 \mathrm{M}$ cacodylate buffer (pH 7.4) for $24 \mathrm{~h}$ and then washed with cacodylate buffer ${ }^{\circ}$. Then they were kept again in glutaraldehyde $2.5 \%$ for other $24 \mathrm{~h}$ and washed with glutaraldehyde $2.5 \%$ in cacodylate buffer (GLC) according to Chambarelli et al. (2008).

\section{Transmission electron microscopy}

Transmission electron microscopy (TEM) imaging and energy-dispersive $X$-ray spectroscopy (EDS) were conducted using a JEOL 2200 FS TEM with attached EDS, at the Advanced Microscopy Center, Michigan State University, USA. Copper grids were coated with ultra thin carbon films. By using the thin film copper grids, the sample could be deposited on the film instead of falling through the mesh of the grid. Grids were then coated with Sundew adhesive in the same manner, using the technique described earlier. Briefly, the copper grids were grasped using sharp electron microscopic forceps and gently brushed against the tentacles of the Sundew. After coating with the adhesive, the samples were dried overnight for subsequent analysis.

\section{Atomic force microscopy}

Atomic force microscopy (AFM) is a very high resolution type of Scanning probe microscopy with demonstrated resolution on the order of fractions of a nanometer, more than 1000 times better than the optical diffraction limit. It is a modern tool for imaging nanostructures. The machine can measure single molecule interaction forces. These forces play an important role in fundamental processes occurring in physical and biological systems.

Atomic force microscopy imaging was conducted using both an Agilent 5500 AFM and an Agilent 6000 ILM/AFM. The purpose of using both systems was to control for potential artifacts, and to allow for microscopic imaging of the samples to determine the targeted scanning areas. In addition, all samples were examined by two independent investigators who prepared their samples separately to further eliminate the possibility of creating artifacts in the data sets. All imaging for both systems was conducted in air in AC mode. Both systems were equipped with intermittent contact mode tips, Budget Sensors ${ }^{\oplus}$ Tap150AL-G, with aluminum reflex coating. The tips had a resonant frequency of $150 \mathrm{kHz}$ and a force constant of $5 \mathrm{~N} / \mathrm{m}$. Due to tip variation, manual sweeps were conducted on all tips prior to scanning to determine the actual frequency of the tip. Prior to scanning, a calibration grid was used to assure that the distance measurements of the Picoview ${ }^{\otimes}$ software were accurate. Publication quality scans were conducted at a scan speed of less than $1 \mathrm{ln} / \mathrm{s}$ and a resolution of $1024 \times 1024$ pixels.

\section{RESULTS}

Field Emission Scanning Electron Microscopy (FE-SEM) images showed the presence of nanoparticles on the body parts of the bees. Figure 1 depicts the nanoparticles detected on the different parts of the worker honey bees (wings, abdomen, and thorax, respectively). The size distribution of the nanoparticles collected from the different parts is between 5-50 nm. The abdomen (Fig. 1b) and the thorax (Fig. 1c) contain smaller sized particles compared with the ones on the wing (Fig. 1a). A little aggregation of the nanoparticles has also been observed which indicates their interactions on the surface. The size distribution of the particles was also confirmed by the TEM images (Fig. 2, A, $B$; as abdomen and thorax of the bees contain similar sized particles, we show them selectiveIy, choosing the best image).

Further clarifications have been seen by Atomic Force Microscopy (AFM). Figure 3 represents 
BHATTHFHARYYH ET Al._N Nanoparticles on the body of Apis dorsata Fabricius
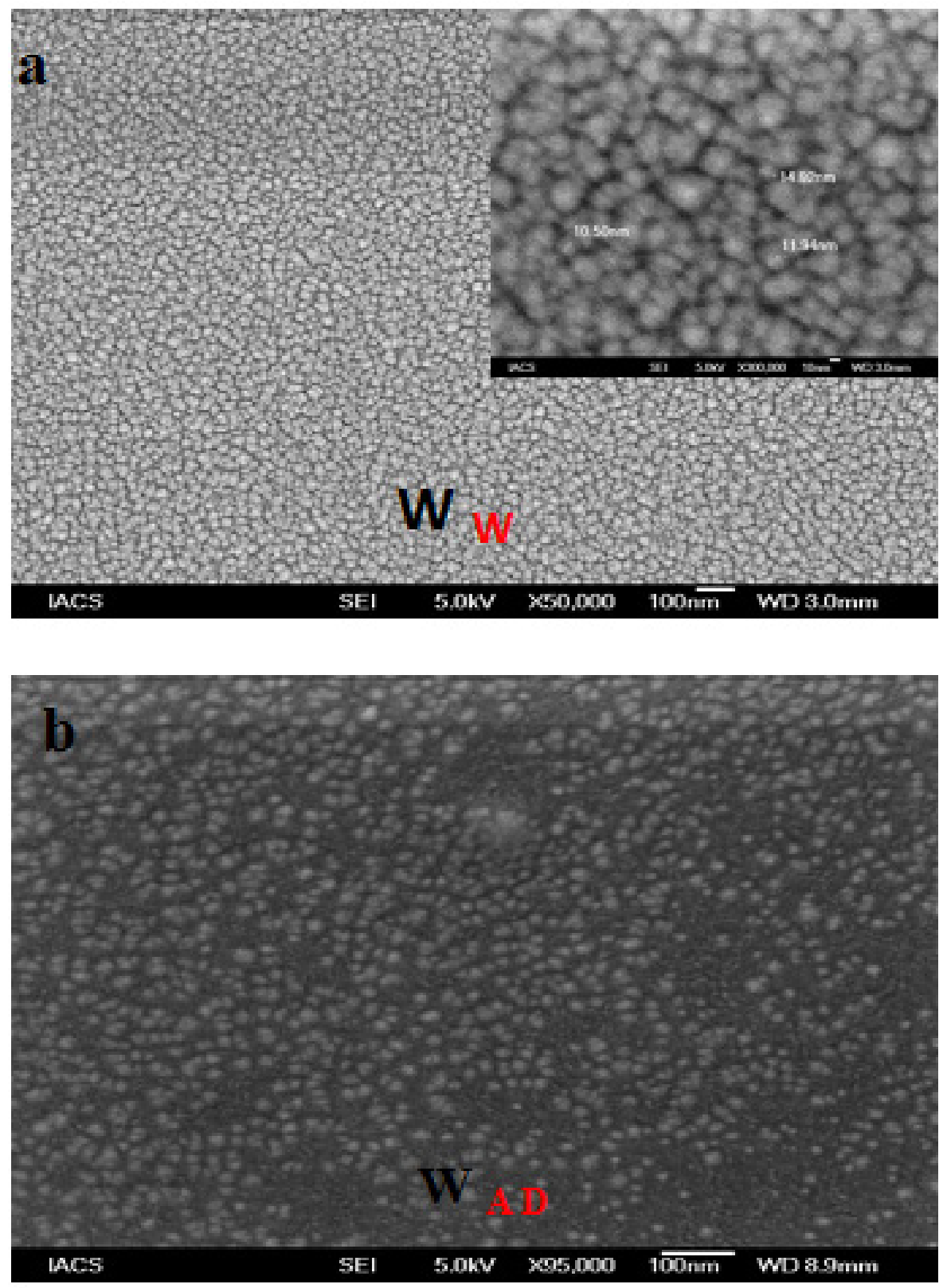

Fig. 1. FE-SEM images of nanoparticles extracted from different parts of Apis dorsata; a. Ww -Worker wing; b. WAD - Worker Abdomen; c. WTH - Worker thorax

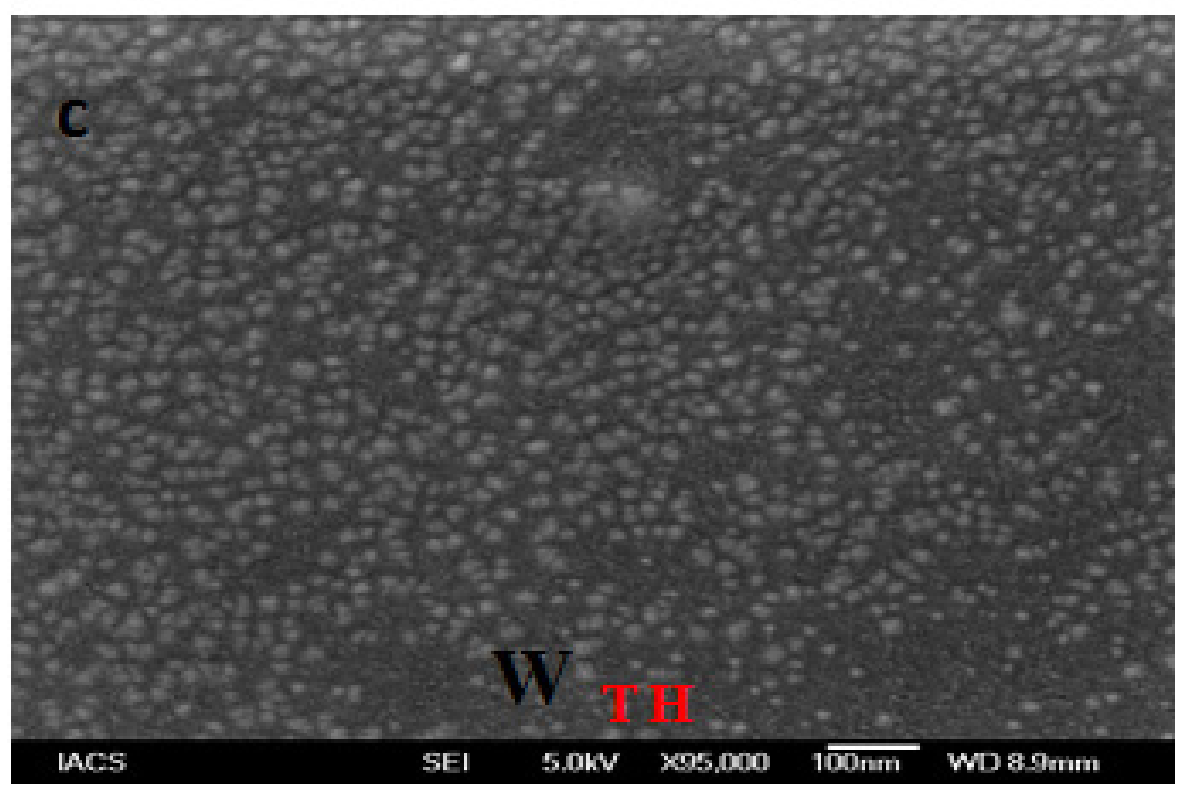


the AFM images for WW (Worker Wing) sample. A topographical image represents the twodimensional distributions of nanoparticles throughout the body matrix (depicted in Fig. 3a). The histrogram in Figure 3b suggests that the particle size distribution of the nanoparticles is around $20 \mathrm{~nm}$. The three dimensional AFM-image shows the particle height on a measured surface (Fig. 3c). Similar observations have been made for the nanoparticles collected from a WAD (Worker Abdomen) sample (Fig. 4). The histogram data (Fig. 4b) show that particles are somehow smaller in size with respect to the WW sample (as also seen in SEM data in Fig. 1). We also need to keep in mind that, in general, the size obtained from an AFM image should be higher than that seen in FE-SEM images because in tapping mode, AFM image particles are somewhat exaggerated. The image in Figure $4 c$ gives almost a similar height for consecutive particles. The diameter of the particles measured

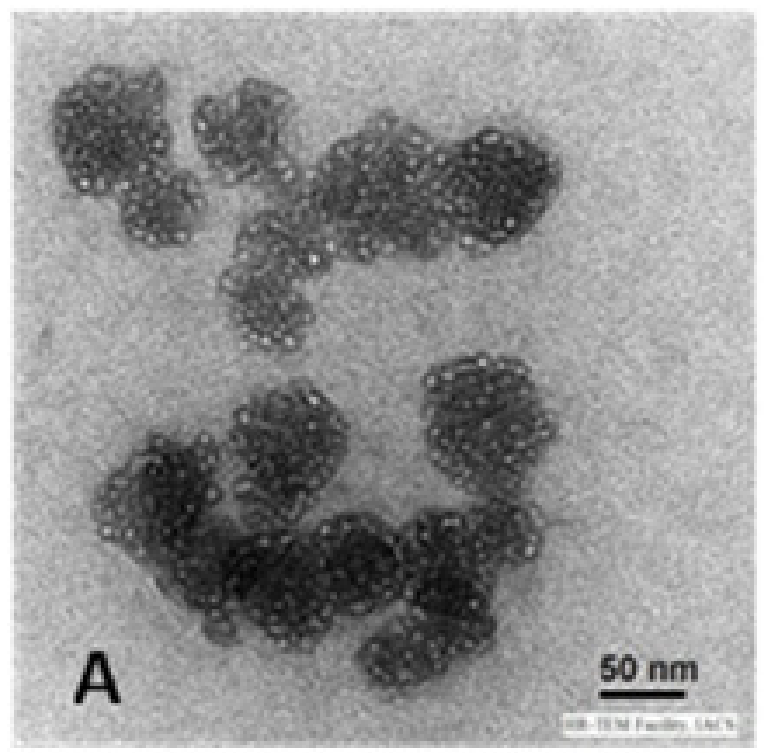

presented in Fig. 6. The presence of calcium in higher amounts, including Si and $\mathrm{P}$, may suggest the presence of calcium silicate and calcium phosphate as nanoparticles. Cu and C elements have also been found but probably represents crystals of cacodylate buffer used in the procedure. It is believed that the $\mathrm{Cu}$ and $\mathrm{C}$ elements come from the TEM grid or from contamination as they are being associated with different eco-condition. Cu and C elements have been found in samples from different nests.

\section{DISCUSSION}

Field Emission Scanning Electron Microscopy (FE-SEM) images have shown the presence of nanoparticles on the body parts of $A$. dorsata bees (wings, abdomen, and thorax). Till now, nanoparticles have never been investigated in $A$. dorsata F. The above work clearly demonstrates the presence of nanoparticles on all three body

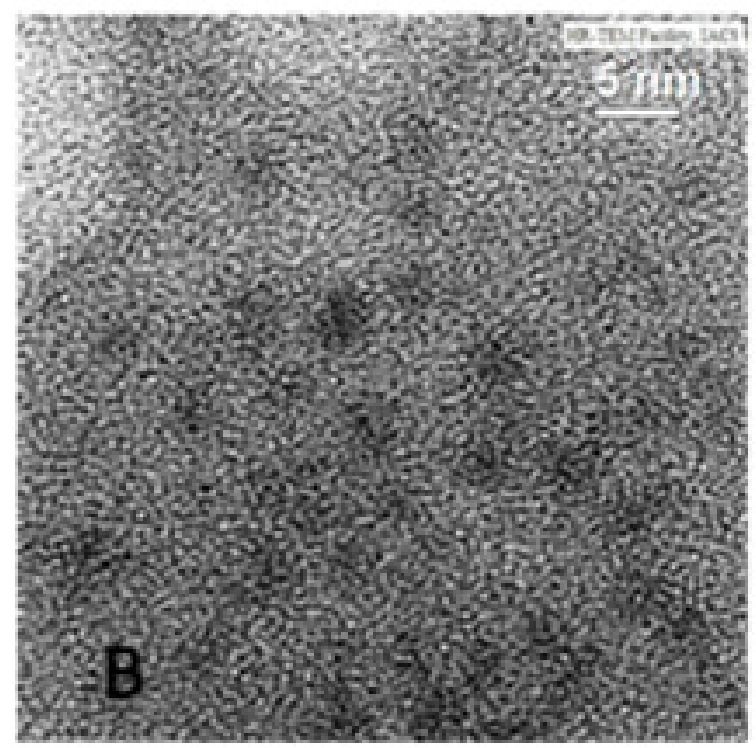

Fig. 2. TEM image showing the size distribution of the nanoparticles Worker wing and Worker thorax; $A$. the biggest and $B$. the smallest nanonparticles

by using two or three consecutive particles (see Fig. 5A, B, for abdomen and thorax, respectively) matches with the particle diameter seen in SEM and TEM data (Fig. 1 and 2).

Furthermore, it was interesting to investigate the nature of the nanoparticles detected. For this reason electron dispersive $X$-ray spectroscopy analysis was performed. The results are parts of the Indian rock bee, although different from the nanoparticles previously reported by other researchers in honey bees, meliponinae bees or other insects (Alves etal., 2004; Wajnberg et al., 2004; Abracado et al., 2005; Desoil et al., 2005; Lucano et al., 2006; Hsu et al., 2007). According to Sharma et al. (2011), the A. mellifera bee's thorax, abdomen and wings contain small 
(244.252) x 191 un y. $1969 \mu \mathrm{n} \times 0.01278 \mathrm{~mm}$

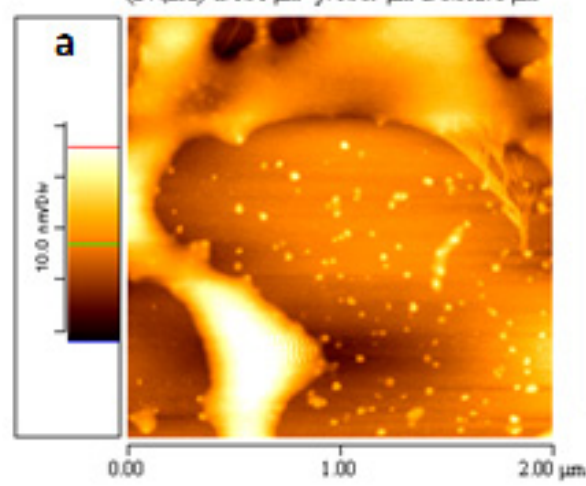

b

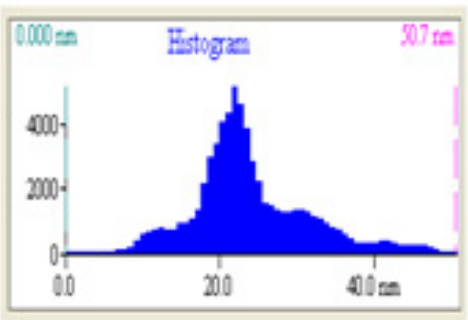

Sample

WW c

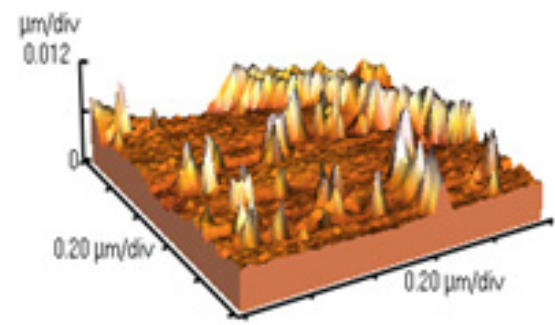

Fig. 3. AFM images of WW -Worker wing; a. in 2D; b. histogram of particle distribution; c. height distributions in $3 D$

to large particles, with a size from 5 to $50 \mathrm{~nm}$. Gould et al. (1980) observed that nanoparticles found in $A$. mellifera abdomens ranged between 30 and $35 \mathrm{~nm}$ in diameter. Particles of that size (around $30 \mathrm{~nm}$ ) are classified as 'large' and were absent in the heads and thoraxes (Desoil et al., 2005). In this study, we found that the nanoparticles on the abdomens of $A$. dorsata have a diameter of about 10 nanometers and they are smaller than those found on the wings of the same bees. The size distribution of the nanoparticles collected from the different parts is between 5-50 nm.

All previous works describe iron nanoparticles on the $A$. mellifera body (Could et al., 1980; Schiff, 1991), as well as on trophocytes (Hsu \& Li, 1994; Hsu et al., 2007; El-Jaick et al., 2001). In $(250,177) \times 4.88 \mu \mathrm{m}$ y. $3.457 \mu \mathrm{m} \approx 0.01199 \mu \mathrm{m}$
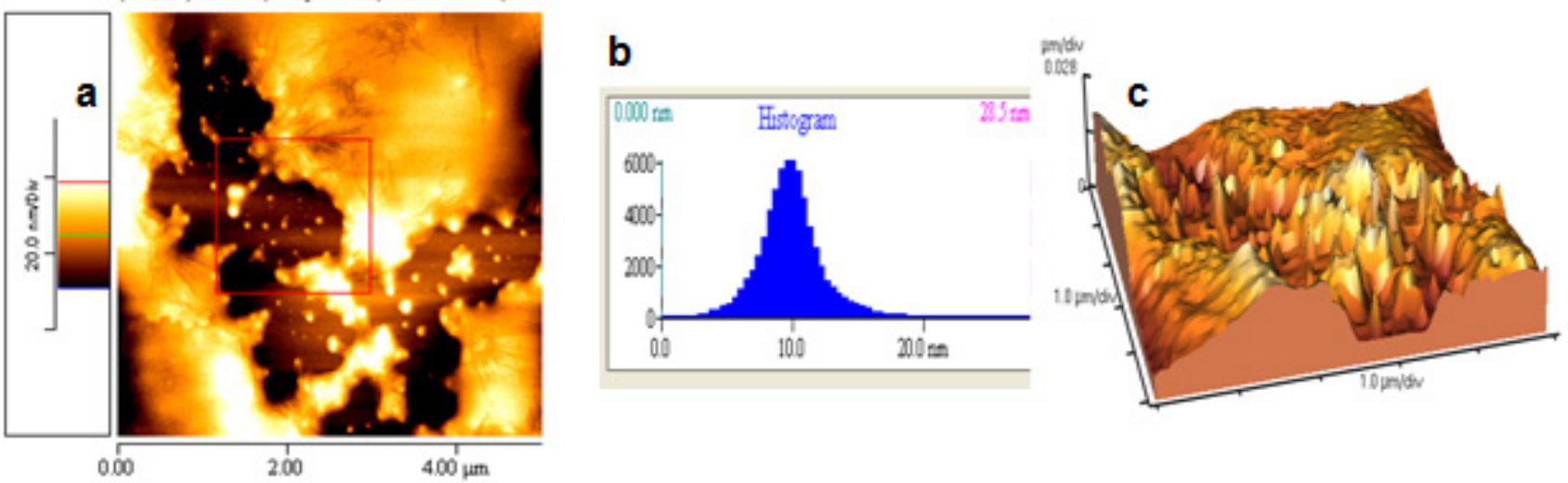

\section{Sample \\ WAD}

our study, we clearly defined that the particles on the body of the $A$. dorsata bee were not iron but most probably calcium silicate and calcium phosphate in nature. Such findings have not been noted before. Still there is no indication, at least from this study, on what the function is of the nanoparticles detected on the body of the Indian rock bee. It is also impossible at this stage, to know where these particles come from, since calcium silicate is, in fact, a white free-flowing powder derived from limestone or diatomaceous earth (fossilised remains of algae) and that calcium phosphate is a mineral found in food.

It is possible that nanoparticles in the insect wings help to increase the aerodynamic effectiveness of the insect. Therefore, the nanopar-

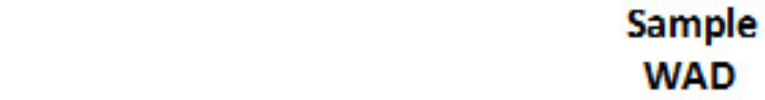

Fig. 4. AFM images of WAD -Worker Abdomen a. in 2D; b. histogram ofparticle distribution; c. height distributions in $3 \mathrm{D}$ 

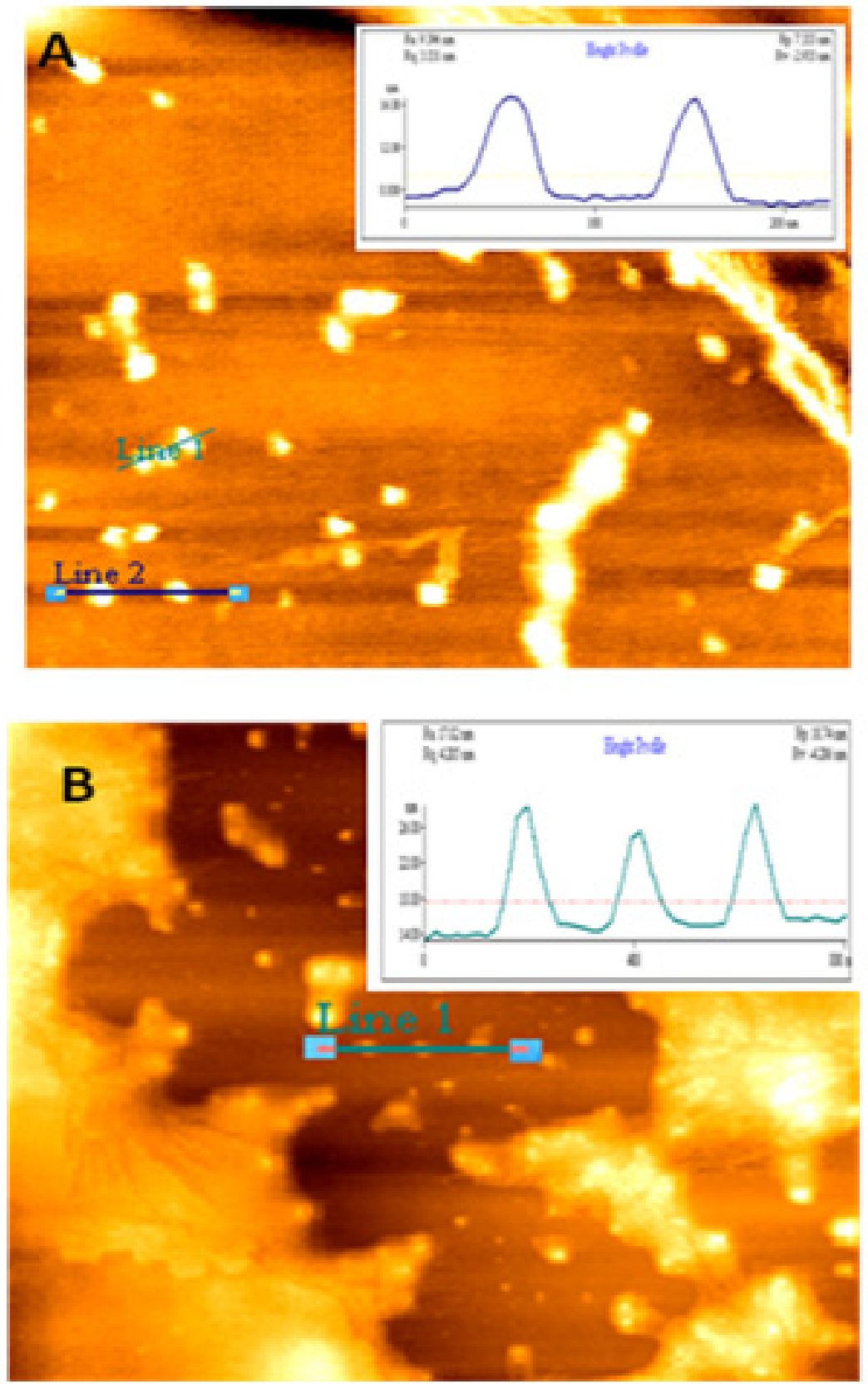

Fig. 5. Obtained diameter of the nanoparticles by using Pro-Scan software for AFM analysis. The measurements were done for two or three consecutive nanoparticles. A. WAD - Worker Abdomen; B. WTH - Worker thorax

ticles might play an important role in pollination efficiency of the giant bee. It is essential to investigate if these nanoparticles play any role in the behavior of $A$. dorsata bees in relation to their orientation (diurnal or nocturnal) (Dyer, 1985), colony migration (Dyer \& Seeley 1994), and absconding or swarming behavior, considering the special environmental conditions in which this particular bee survives.

This is the first study to suggest that the Apis dorsata honey bee posses calcium silicate nanoparticles on their body surface. A future study should make comparisons between Apis dorsata and Apis mellifera as well as to define the nature of these nanoparticles in order to allow us to understand their use by Apis dorsata. Future work in conservation studies of the Apis dorsata species might also help. These nanoparticles are sufficiently small enough to move inside the body without disrupting normal functions and can access spaces unapproachable by other pathological means. This means that nanoparticles could be used in an application for insect pest management, instead of 


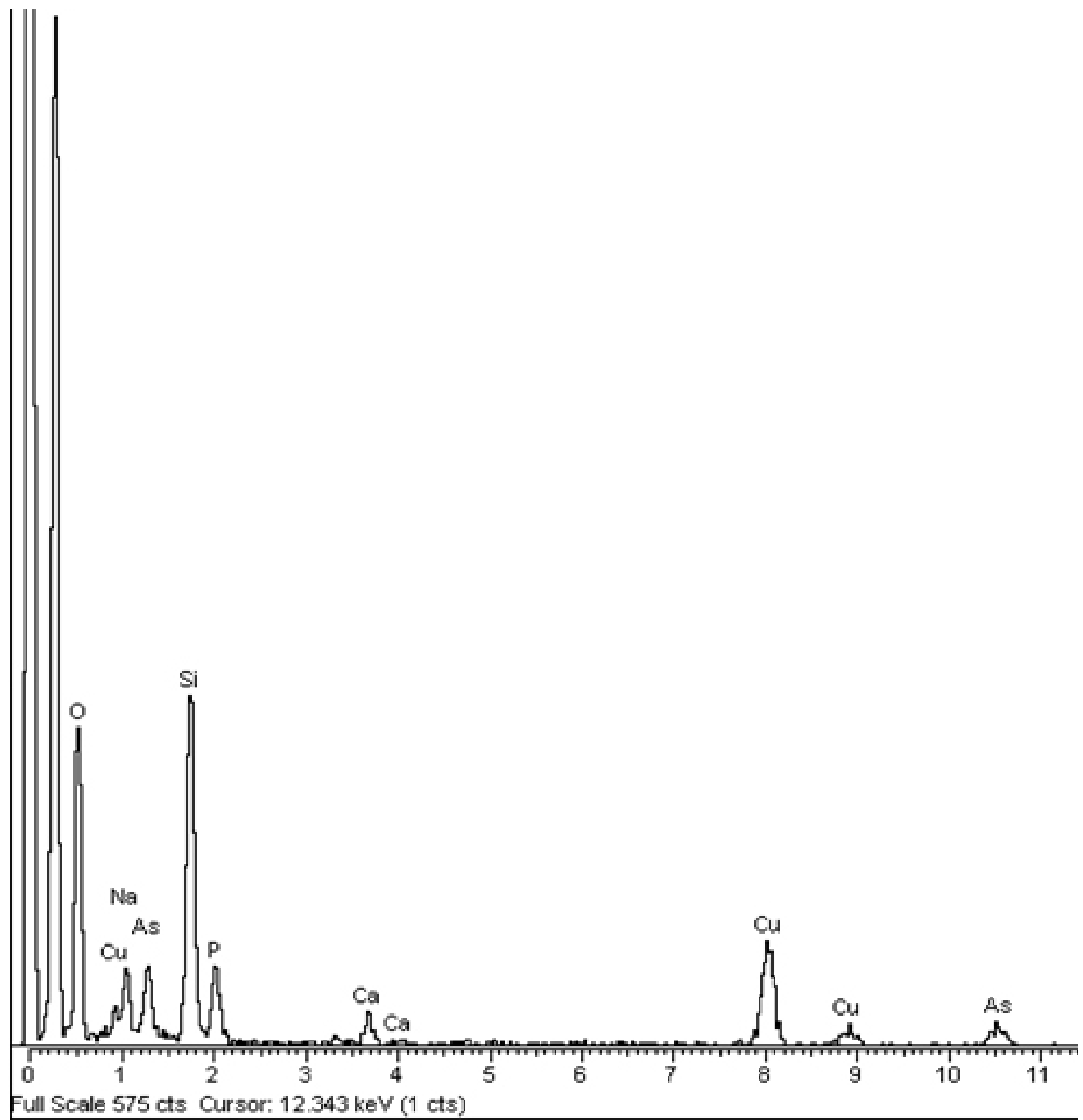

Fig. 6. Presence of calcium in higher amounts, including Si and P, may suggest the presence of calcium silicate and calcium phosphate as nanoparticles. Cu and C elements have come from TEM grid

synthetic chemicals (see also Bhattacharyya et made this research possible. Our thanks also to al., 2010; Gul et al., 2014). Dr. Mahbub Hasan - Rajshahi University, whose knowledge of insect 'nano' and interest in new things, transformed an interesting idea into a ACKNOWLEDGEMENTS

The authors would like to thank Dr. Alyssa Y. reality. We finally wish to thank the anonymous Stark - The University of Akron and Dr. H.D.C. Phillips - University of Delaware for their support, referees for their valuable comments and suggestions which improved the article.

mentorship, and constructive feedback that 


\section{J. APlC. SOL. YOL. G0 NIO. 12016}

\section{REFERENCES}

Abracado, L. G., Esquivel, D. M. S., Alves O. C., \& Wajnberg E. (2005). Magnetic material in head, thorax and abdomen of Solenopsis substituta ants: a ferromagnetic resonance (FMR) study. Journal of Magnetic Resonance, $775(2), 309-316$. http://doi. org/10.1016/j.jmr.2005.05.006

Alves, O. C., Wajnberg, E., de Oliveira J. F., \& Esquivel D. M. S. (2004). Magnetic material arrangement in oriented termites: a magnetic resonance study. Journal of Magnetic Resonance, 168(2), 246-251. http:// doi.org/10.1016/j.jmr.2004.03.010

Bhattacharyya, A., Gosh, M., Chinnaswamy, K. P., Sen, P.,, Barik, B., Kundu, P., Mandal, \& S. (2008). Nanoparticle (allelochemicals) and silkworm physiology. In Chinnaswamy, K. P., Vijaya, B. R. A. (Eds). Recent Trends in Seribiotechnology. Bangalore, India. pp. 58-63.

Bhattacharyya, A., Bhaumik, A., Usha Rani, P., Mandal, S., \& Epidi T. T. (2010). Nano-particles - A recent approach to insect pest control. African Journal of Biotechnology, 924), 3489-3493. http://doi. org/10.5897/AJBx09.021

Binhi, V. N. (2004). Stochastic dynamics of magnetic nanaoparticles and a mechanism of biological orientation in the geomagnetic field. arXiv: physics/04122158v1. http://doi.org/10.1209/epl/ i2004-10525-6

Desoil, M., Gillis, P., Gossuin, Y., Pankhurst, Q. A., \& Hautot D. (2005). Definitive identification of magnetite nanoparticles in the abdomen of the honeybee Apis mellifera. Journal of Physics, Conference Series 17, 45-49. http://doi.org/10.1088/17426596/17/1/007

Dyer, F. C. (1985). Nocturnal orientation by the Asian honeybee, Apis dorsata. Animal Behaviour, 33(3), 769-774. http://doi.org/10.1016/S00033472(85)80009-9

Dyer, F. C., \& Seeley T. D. (1994). Colony migration in the tropical honeybee Apis dorsata F. (Hymenop- tera: Apidae). Insectes Sociaux, 47(2), 129-140. http://doi.org/10.1007/BF01240473

El-Jaick, L.J,, Acosta-Avalos, D., Esquivel, D. M. S., Wajnberg, E., \& Linhares, M. P. (2001). Electron paramagnetic resonance study of honeybee Apis melifera abdomens. European Biophysics Journal, 29(8), 579-586. http://doi.org/10.1007/ s002490000115

Frisch, K. von (1 967). The dance language and orientation of bees. Harvard University Press: Cambridge.

Gallai, N., Salles, J. M., Settele, J., \& Vaissière, B. E. (2009). Economic valuation of the vulnerability of world agriculture confronted with pollinator decline. Ecological Economics, 68(3), 810-821. http://doi. org/10.1016/j.ecolecon.2008.06.014

Gould, J. L. (1976). The dance-language controversy. Quarterly Review of Biology, 51(2), 211-244. http://doi.org/10.1086/409309

Gould, J. L., Kirschvink, J. L., Deffeyes, K. S., \& Brines, M. L. (1980). Orientation of Demagnetized Bees. Journal of Experimental Biology, 86(1), 1-8.

Gul, H. T., Saeed, S., Khan, F. Z. A., \& Manzoor, S. A. (2014). Potential of Nanotechnology in Agriculture and Crop Protection: A Review. Applied Sciences and Business Economics, 7(2), 23-28.

Hsu, C. Y., \& Li, C. W. (1994). Magnetoreception in honeybees. Science, 265, 95-97. http://doi. org/10.1126/science.265.5168.95

Hsu, C. Y., Ko, F. Y., Li, C. W., Fann, K., \& Lue, J. T. (2007). Magnetoreception System in Honeybees (Apis mellifera). PLoS One, 2(4), e395. http://doi.org/10.1371. journal.pone.000039

Koeninger, N., \& Koeninger, G. (1990). Evolution of reproductive behavior in honeybees. In Veeresh, G. K., Mallik, B., Viraktamath, C. A. (Eds). Social Insects and Environment. Oxford Univ. Press and OBH; Delhi, India pp. 101-102.

Leiderer, P., \& Dekorsy, T. (2008). Interactions of nan- 
oparticles and surfaces Tag der mÄundlichen PrÄufung: 25. April. URL: http://www. ub. unikonstanz. de/kops/volltexte/2008/5387.

Lindauer, H., \& Martin, Z. (1968). Die Schwereorientierung der Bienen unter dem Einfluß des Erdmagnetfeldes. Journal of Comparative Physioogy $A$, 6033), 219-243. http://doi.org/10.1007/ $\mathrm{BF} 00298600$

Lucano, M. J., Cernicchiaro, G., Wajnberg, E., \& Esquivel, D. M. (2006). Stingless bee antennae: a magnetic sensory organ? Biometals, 19, 295-300. http://doi. org/10.1 007/s 10534-005-0520-4.2

Nykypanchuk, D., Maye, M. M., van der Lelie, D., \& Gang O. (2008). DNA-guided crystallization of colloidal nanoparticles. Nature, 451(7178), 549-552.

Neupane, K. R., Woyke, J., \& Poudel, S. M. (2013). behavior of giant honeybee Apis dorsata. In Proceedings of International Beekeeping Congress of APIMONDIA, 29 September - 4 October 2013, Kyiv, Ukraine.

Ruttner, F. (1988). Breeding techniques and selection for breeding of the honeybee. British Isles Bee Breeders Association / Ehrenwirth Verlag; Munich, Germany.
Sabbour, M. M. (2013). Entomotoxicity assay of Nano-particle 3-(Zinc oxide ZnO) Against Sitophilus oryzae under laboratory and store conditions in Egypt. Scientific Research Reports, 7(2), 51-57.

Schiff, H. (1991). Modulation of spike frequencies by varying the ambient magnetic field and magnetite candidates in bees (Apis mellifera). Comparative Biochemistry and Physiology A, 10044), 975.

Sharma, P. K., Dutta, K., \& Pandey, A. C. (201 1). Advances in multifunctional magnetic nanoparticles. Advance Material Letters, 2(4), 246-263. http://doi. org/10.5185/amlett.201 1.indias214

Wajnberg, E." Cernicchiaro, G., Esquivel, \& D. M. S. (2004). Antennae: the strongest magnetic part of the migratory ant. Biometals, 17, 467-470. http:// doi.org/10.1023/B:BIOM.0000029443.93732.62 